\title{
A GERAÇÃO DE 45
}

\author{
Édison José da Costa*
}

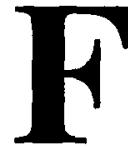

ugindo ao artificialismo que sufocava a produção parnasiana ainda significativa no cenário multifacetado da poesia nacional nas duas primeiras décadas do século 20, a geração fundadora do Modernismo brasileiro havia defendido a necessidade de o artista estar comprometido essencialmente com a poesia e não com o verso. Reconhecia como fundamental a recusa dos modelos composicionais preestabelecidos a fim de o artista liberar-se para a captação e a representação da modernidade. Lembre-se Manuel Bandeira a declarar, em sua "Poética", estar farto "de todo lirismo que capitula ao que quer que seja fora de si mesmo". Veja-se, no "Prefácio interessantíssimo", Mário de Andrade a defender que o lirismo "cria frases que são versos inteiros, sem prejuizo de medir tantas sílabas, com acentuação determinada".

Essa postura dificilmente se deixa reconhecer, entretanto, no trabalho que os poetas da Geração de 45 desenvolvem passados 23 anos da realização da Semana de Arte Moderna. Alceu Amoroso Lima, por exemplo, já em 1956 chama a atenção para "o primado do verso sobre a poesia", que vê estabelecido

* Universidade Federal do Paraná

1 BANDEIRA, Manuel. Poética. In: Estrela da vida inteira. 2. ed. Rio de Janeiro: J. Olympio, 1970. p. 108.

2 ANDRADE, Mário de. Prefácio interessantíssimo. In: Poesias completas, Ed. crítica de Diléa Manfio. Belo Horizonte: Itatiaia/São Paulo: Edusp, 1987. p. 59-77. 1956. p. 124.

3 LIMA, Alceu Amoroso. Quadro sintético da literatura brasileira. Rio de Janeiro: Agir, 
nas publicações do grupo. E José Guilherme Merquior, em 1962, acusa mesmo a Geração de 45 "pelo crime de ter traído a poesia". ${ }^{4}$ Este ensaio quer focalizar esse momento do desenvolvimento literário brasileiro a partir do contato com poemas publicados nos anos 40 por representantes do grupo.

Entre 29 de abril e 2 de maio de 1948, ocupando sucessivamente, para suas sessões, o auditório da Biblioteca Municipal de São Paulo, o Museu de Arte, o bar do Teatro Municipal, o auditório da Escola Normal Caetano de Campos e o auditório de $A$ Gazeta, realiza-se, idealizado e organizado por Domingos Carvalho da Silva, o I Congresso Paulista de Poesia. A motivação para o empreendimento é anunciada de maneira clara por seu idealizador em conferência que intitula "Há uma Nova Poesia no Brasil" e na qual propõe a denominação que passa a designar o grupo de poetas surgidos ao redor do término da 2. a Guerra Mundial. Domingos Carvalho da Silva tem em vista livros que Lêdo Ivo, Bueno de Rivera, João Cabral de Melo Neto, Geraldo Vidigal, Péricles Eugênio da Silva Ramos e ele próprio haviam publicado. Entrevista com o poeta, divulgada pelo Correio Paulistano em 8 de maio, destaca a participação de Oswald de Andrade e Patrícia Galvão em debates que opuseram 45 e 22 e deixa no ar indicação pela qual se pode ter idéia da atmosfera reinante: o entrevistado faz questão de recordar "que o sr. Osvaldo de Andrade me chamou 'dono do Congresso",.

Aos "novos" poetas inspiradores da conferência acabam associando-se, a partir do congresso, os "novíssimos", divulgados desde 1948 pelo Clube de Poesia de São Paulo, entre os quais estão Haroldo de Campos, Décio Pignatari, Zulmira Tavares e Mário Chamie, poetas cujo trabalho posterior acabaria por assumir orientação significativamente independente. Cyro Pimentel, em quadro retrospectivo que apresenta em 1983, destaca a ligação inicial de Haroldo de Campos e Décio Pignatari com a Geração de 45, indicando que, se logo se afastaram para seguir seus próprios passos, não deixaram, é o caso de Pignatari, de dedicar o primeiro livro, em 1950, a Péricles Eugênio da Silva Ramos, e de, é o caso de Haroldo de Campos, receber de integrante da Geração o encaminhamento para Cummings e Pound. ${ }^{6}$

Domingos Carvalho da Silva usa critério simplesmente cronológico quando relaciona João Cabral de Melo Neto entre os poetas da Geração de 45.

4 MERQUIOR, José Guilherme. Falência da poesia. In: Razão do poema. Rio de Janeiro: Civilização Brasileira, 1965. p. 33-40.

5 SILVA, Domingos Carvalho da. A batalha entre 22 e 45 determinou o itinerário do Congresso de Poesia: entrevista. Revista de Poesia e Crítica. Brasília, v. 9, n. 11, p. 105-108, set. 1985.

6 PIMENTEL, Cyro. O Clube de Poesia, a Geração de 45 e outras tendências. Revista de Poesia e Crítica. Brasília, v. 8, n. 10, p. 61-68, nov. 1984. 
Faltava-lhe evidentemente a visão distanciada que agora, passados cinquienta anos, permite distinguir a poesia cabralina daquela de seus contemporâneos. De outro lado, poetas não mencionados pelo conferencista vêm a mostrar-se igualmente identificados com a Geração, merecendo certamente destaque José Paulo Moreira da Fonseca e Geir Campos, ambos com estréia depois de 45 - em 1947 e 1950 respectivamente.

Lêdo Ivo publica quatro livros nos anos 40: As imaginações em 1944, Ode e elegia em 1945, Ode ao crepúsculo em 1948, Acontecimento do soneto e Cântico em 1949. Um impulso criador literariamente desencadeado deixa-se manifestar em títulos como esses, geralmente estabelecidos desde perspectiva essencialmente estética que apresenta não a linha temática mas o conteúdo formal do volume. Dois dos que mais claramente trazem esse sentido à configuração - Ode e elegia e Acontecimento do soneto - fornecem os poemas que a seguir serão considerados.

O poeta retira de solução formal previamente estabelecida o roteiro a que submete a manifestação do lirismo em Acontecimento do soneto. Dá curso, no desenrolar do volume, à proposta que explicita metalingüisticamente em texto de abertura:

[...] e serei, mergulhado no passado,
cada vez mais moderno e mais antigo.

Ele quer que seu canto escape ao tempo: afastando-se do registro mais concreto e individualizado, manifesta-se em plano que traz à cena o universal. Veja-se a primeira quadra do "Soneto de abril":

Agora que é abril, e o mar se ausenta secando-se em si mesmo como um pranto, vejo que o amor que te dedico aumenta seguindo a trilha de meu próprio espanto. ${ }^{8}$

Dicção caracterizada pelo despojamento, articula motivos intemporais, retomando valores clássicos e modelo petrarquiano. Exalta-se, dessa forma, ao

7 IVO, Lêdo. Central poética. Rio de Janeiro: Nova Aguilar, 1976. p. 47.

8 Ibid., p. 47. 
mesmo tempo que a figura da amada, tematicamente focalizada, também o legado estético que lhe dá acolhimento.

A superação, simultaneamente, da fase revolucionária do Modernismo brasileiro e do desleixamento formal de representantes do grupo espiritualista é o sentido que orienta a produção do poeta. Universalismo e artesanato impõemse nesse momento em que a experiência concreta da guerra recém-encerrada impulsiona ao cultivo da fraternidade e da beleza, momento em que o sepultamento do Estado Novo getulista convida ao exorcismo geral do passado imediato brasileiro - o literário inclusive.

Ode e elegia permite o aprofundamento da questão. No poema "Ode", por exemplo, o formalismo orienta a composição do enunciado, fazendo desenvolver-se de forma ordenada e coerente o pensamento, não obstante o acento abstratizante. Repare-se em seus metros iniciais:

São sombras projetadas em minha alma que renascem no encanto do jardim: contemplo sombras que, no mar sem calma, lembram jovens coqueiros arrastados por ondas que, jogadas contra mim, os preferissem por estranhos fados.

O verso, forma a ser preenchida, sobrepõe-se ao impulso lírico e o olhar a partir do qual motivos e imagens encontram manifestação revela-se intelectualmente impulsionado. $O$ poema desenvolve-se de modo solene e ao mesmo tempo grave, assinalado por sentido de construção que lhe abranda a emoção.

$\mathrm{O}$ envolvimento do poeta com o sublime faz-se objetivamente em "Descoberta do inefável":

Sem o inefável, que valoriza as mãos e faz o Amor voar, não poderei descer de repente ao inferno de seu corpo nu. ${ }^{10}$

O discurso compõe-se complexamente, como no exemplo anterior, submetendo a moldura lógica o pensamento. $O$ poeta, percorrendo analiticamente o território da sublimidade, imprime precisão e nitidez à linguagem.

9 IVO, op. cit., p. 35.

10 Ibid., p. 40. 
O aproveitamento do verso longo não metrificado deixa perceber da mesma forma o controle da razão sobre a emoção. Atente-se para o momento inicial de "Elegia didática":

\section{Pensa nas moças mortas, que entregaram à terra um segredo ardentemente ambicionado pelos homens, e nos colegiais que amam com a maior pureza as jovens vizinhas que os namorados levam para os grandes escuros da cidade. ${ }^{11}$}

Não se encontra aí o movimento encantatório do verso claudeliano que o grupo espiritualista havia cultivado. $O$ período racionalmente organizado tampouco abre espaço para a manifestação da visão rimbaudiana. $O$ verso longo do poeta, ajustado à qualificação anunciada pelo título do poema, recorta "didaticamente" momentos sintáticos do discurso poemático, realizando-se em linearidade e clareza.

A poesia de Lêdo Ivo integra, nos anos 40 , momento literário caracterizado pelo arrefecimento do vigor revolucionário modernista. Corresponde a encaminhamento que se impõe à observação mesmo na produção de nomes históricos do movimento, também voltados nesse momento para a valorização da disciplina e para a concepção construtivista do fazer poético. Distintamente, porém, da motivação interna que nesse caso atua, decorrente do amadurecimento da própria poesia modernista e pela qual se conciliam dialeticamente a inquietação criadora e a preocupação formal, sobrepõe-se, no trabalho da Geração de 45 , a postura passadista, a nuança parnasiana contra a qual se havia justamente batido o Modernismo. A incompreensão em face de conquistas fundamentais da primeira geração modernista manifesta-se indistintamente em todos os que se deixam abrigar sob a expressão cunhada em 1948 por Domingos Carvalho da Silva.

Inquietações e expectativas são compartilhadas pelos integrantes da Geração, tanto quanto soluções e encaminhamentos. Veja-se, de Péricles Eugênio da Silva Ramos, a estrofe inicial de "O mundo, o novo mundo", poema publicado em Lamentação floral, de 1946:

\section{Porque tentasse decifrar os signos da matéria, com seu rumor de concha sob a forma silenciosa;}

11 IVO, op. cit., p. 41. 
porque sem olhos se entregasse a tal empenho, os pés feriu à margem do caminho

dilacerou as mãos nas grimpas da montanha. ${ }^{12}$

O verso longo do poeta desenvolve-se de maneira grave e compenetrada, ordenando os impulsos significativos do discurso. A clareza caracteriza o dizer que se assenta em imagens e procura a elevação, intelectualmente conduzido e dimensionado. Motivos e vocabulário convencionalmente líricos assinalam a aristocratização do campo do poético e ao mesmo tempo o primado do estético.

"Natureza morta", por sua vez, incluída por José Paulo Moreira da Fonseca em Elegia diurna, de 1947, tem como tema a própria obra de arte. Tome-se a primeira estrofe:

No outro termo - a cor -

Terrosa, com lenhos obscuros

Onde resplandece (inércia)

Aquele fugaz rubor de pomos. ${ }^{13}$

O campo do poético fecha-se aqui também tematicamente. À arte interessa a própria arte. A concepção do poema como construção impõe-se ostensivamente, neste caso, assegurando o comprometimento com a beleza. Observe-se que a intercalação de motivo em meio ao contexto oracional, no terceiro verso, mostra o poeta atento à programação estética do poema: com inércia, motivo paronomasticamente concebido, concretiza-se também fonicamente a suspensão ou retardamento da sequiência significativa, pois, retomando configuração fonêmica imediatamente anterior, continua soando e cintilando nele o vocábulo que o precede.

O contato com poemas escritos por autores relacionados, nos anos 40 , com a Geração de 45, traz à revelação neste ensaio valores ou encaminhamentos que se pode considerar comuns e portanto representativos da poesia que o grupo como um todo então avalizava. A Geração de 45 tem a caracterizá-la, e intensamente, a preocupação com a realização formal do poema. $O$ artesanato marca sua relação com o texto poemático, que se impõe como construção,

12 RAMOS, Péricles Eugênio da Silva. O mundo, o novo mundo. In: COUTINHO, Afrânio (Org.). Antologia brasileira de literatura. 2. ed. Rio de Janeiro: Livros Escolares, 1967. v. 2. p. 225-226.

13 FONSECA, José Paulo Moreira da. Natureza morta. In: COUTINHO, Antologia... p. 233. 
realidade objetivamente consistente e autônoma. Cultuando a beleza e destacando na obra literária seu valor de arte, o poeta entende-se sobretudo um esteta. Procura, nestas circunstâncias, objetivar sua relação com o poema, conduzindolhe o desenvolvimento mais intelectual que emocionalmente, pontuando-o com a precisão e o rigor.

A Geração de 45 procura o vocábulo nobre, a imagem rara, e cultiva a forma fixa. Fugindo ao descontrole e ao prosaísmo, impōe-se contudo um decoro que lhe pasteuriza em certa medida o dizer. $O$ verso, nesses termos, sobrepõe-se ao impulso lírico, da mesma forma que se gramaticaliza o discurso, abranda-se a emoção e a manifestação pessoal, subjetiva, dá lugar a uma dicção universalizante. Opostamente à atuação renovadora e dessacralizante que se costuma associar ao fazer modernista, a Geração de 45 traz à cena um modo de ser conservador, bem-comportado, dificilmente revolucionário. $\mathrm{O}$ balanço da contribuição da Geração de 45 para o processo de amadurecimento da poesia brasileira traz à evidência, eloqüentemente, essa recusa, estratégica e programática, em reconhecer o impacto fecundador da explosão modernista. Atento aos fatos e perseguindo a imparcialidade, Alfredo Bosi afere, com precisão, o sentido "bivalente" da atuação do grupo, desvelando a duplicidade de uma contribuição que se apresenta "negativa enquanto subestimava o que o modernismo trouxera de liberação e de enriquecimento à cultura nacional; positiva, enquanto repropunha alguns problemas importantes de poesia". ${ }^{14}$

\section{RESUMO}

Este estudo focaliza poemas publicados, nos anos 40, por Lêdo Ivo, Péricles Eugênio da Silva Ramos e José Paulo Moreira da Fonseca, tentando apreender traços definidores da Geração de 45.

Palavras-chave: Geração de 45, poesia brasileira, Lêdo Ivo.

14 BOSI, Alfredo. História concisa da literatura brasileira. 3. ed. São Paulo: Cultrix, 1981. p. 520. 


\begin{abstract}
This essay analyses poems by Lêdo Ivo, Péricles Eugênio da Silva Ramos e José Paulo Moreira da Fonseca, trying to point out characteristics of the Geração de 45.

Key words: Geração de 45, Brazilian poetry, Lêdo Ivo.
\end{abstract}

\title{
REFERÊNCIAS BIBLIOGRÁFICAS
}

ANDRADE, Mário de. Poesias completas. Ed. crítica de Diléa Manfio. Belo Horizonte: Itatiaia, São Paulo: Edusp, 1987.

BANDEIRA, Manuel. Estrela da vida inteira. 2. ed. Rio de Janeiro: J. Olympio, 1970. BOSI, Alfredo. História concisa da literatura brasileira. 3. ed. São Paulo: Cultrix, 1981. COUTINHO, Afrânio (Org.). Antologia brasileira de literatura. 2. ed. Rio de Janeiro: Livros Escolares, 1967. v. 2.

IVO, Lêdo. Central poética. Rio de Janeiro: Nova Aguilar, 1976.

LIMA, Alceu Amoroso. Quadro sintético da literatura brasileira. Rio de Janeiro: Agir, 1956.

MERQUIOR, José Guilherme. Razão do poema. Rio de Janeiro: Civilização Brasileira, 1965.

REVISTA de Poesia e Crítica. Brasília, v. 8, n. 10, nov. 1984, 92 p.

REVISTA de Poesia e Crítica. Brasília, v. 9, n. 11, set. 1985, 148 p. 